\title{
MULTIMEDIA INTERAKTIF PENGENALAN HEWAN DAN TUMBUHAN LANGKA MENGGUNAKAN MODEL TUTORIAL
}

\author{
Evaliata Br Sembiring( ${ }^{(1)}$, Dwi Wahyuni ${ }^{(2)}$, dan Wenang Anurogo ${ }^{(3)}$ \\ Teknik Multimedia dan Jaringan, Politeknik Negeri Batam ${ }^{(1,2)}$ \\ Teknik Geomatika, Politeknik Negeri Batam ${ }^{(3)}$ \\ Jl. Ahmad Yani, Batam Center, Batam, 2946I, Indonesia \\ Email: (I) eva@polibatam.ac.id, (2)dwahyuni604@gmail.com, (3)wenang@polibatam.ac.id
}

\begin{abstract}
Knowledge of endangered animals and plants is very important for children. Material about those two begins to be studied in class III at the elementary school. A book is used as a medium to deliver the materials. This resulted in a lack of understanding of students toward knowledge about endangered animals and plants. One of the solutions being made is to use the interactive learning media. This paper elaborates on the creation of interactive multimedia learning containing text, images, sound, and animation of 2D. The research shows that: (1) Interactive multimedia is created in the form of tutorials and practice questions in the .exe format so that their use does not depend on a specific software; (2) the aspect of interest-ness of the multimedia is $82.4 \%$; (3) pretest and post-tests show that the interactive multimedia experience increased the student understanding, namely achieving $50 \%$ with the average value of the students' score reaches $83.3 \%$.
\end{abstract}

Keywords : interactive multimedia, endangerd animals, endangered plants

\section{PENDAHULUAN}

Hewan dan tumbuhan langka adalah suatu kondisi dari populasi hewan dan tumbuhan yang hampir punah, bahkan sangat sedikit jumlahnya. Beberapa hewan yang sudah disebut langka saat ini seperti harimau, komodo, dan lainnya. Sama halnya dengan tumbuhan yang sudah langka adalah raflesia, bunga bangkai, dan sebagainya. Hewan dan tumbuhan langka ini tidak bisa ditemukan lagi di alam bebas dan salah satu penyebab kelangkaannya adalah kerusakan habitat sehingga tidak mampu mengembalikan jumlah populasinya (Permana, dkk, 2016). Pengetahuan tentang hewan dan tumbuhan langka tetap dijadikan sebagai materi pembelajaran di sekolah, khususnya pada tingkat dasar. Salah satu pemikiran tentang pentingnya pengetahuan tentang hewan dan tumbuhan langka bagi anak-anak adalah sebagai pembelajaran agar dapat menjaga lingkungan tetap lestari. Selain itu, mengetahui adanya hewan dan tumbuhan yang langka sehingga perlu dijaga dan dilestarikan agar tidak sampai punah. Berdasarkan KBBI, proses pembelajaran setiap individu untuk mendapatkan pengetahuan dan pemahaman sebuah obyek tertentu yang lebih spesifik berakibat pada pola pikir, perilaku dan akhlak. Oleh sebab itu, materi tentang hewan dan tumbuhan langka secara umum sudah mulai diperkenalkan di sekolah dasar melalui melalui pelajaran Ilmu Pengetahuan Alam (IPA).

Media yang digunakan umumnya adalah buku. Media ini sangat klasik atau tradisional dibandingkan dengan perkembangan teknologi pada jaman yang disebut jaman now. Penggunaan buku memberi kesan biasa bagi siswa sehingga kurang diminati dan berdampak pada kurangnya pemahaman siswa dalam pelaksanaan pembelajaran 
yang dilakukan. Salah satu pemanfaatan teknologi yang secara umum dapat dimiliki dan dimanfaatkan oleh guru maupun siswa adalah PC, laptop atau tablet. Oleh sebab itu, media pembelajaran IPA khususnya tentang hewan dan tumbuhan langka ini dapat memanfaatkan multimedia pembelajaran secara interaktif. Media ini dapat digunakan sebagai alat pengontrol bagi pengguna dengan memanfaatkan komputer sehingga memungkinkan pengguna untuk berinteraksi dan berkomunikasi (Abidin, dkk, 2013). Media pembelajaran interaktif dipandang dapat menciptakan proses belajar yang menarik, interaktif dan menyenangkan (permana dkk, 2014), karena media yang dikembangkan dengan pemanfaatan teknologi komputer ini dapat menyampaikan materi pembelajaran secara tekstual, audio dan visual (Rosyida, 2017). Multimedia interaktif juga dapat meningkatkan motivasi belajar untuk menguasai materi pelajaran secara utuh, dapat mengembangkan kemampuan dalam berinteraksi langsung dengan lingkungan dan dapat digunakan sebagai sumber belajar yang berbasis ICT memungkinkan siswa dapat belajar mandiri sesuai kemampuan dan minatnya (Prayoga, Sudarma, \& Tegeh, 2016). Bahkan multimedia interaktif cocok digunakan sebagai media pembelajaran karena dapat meningkatkan daya tarik dan pemahaman anak-anak khususnya usia 6-12 tahun karena menerapkan sistem belajar dalam bentuk permainan atau kuis (Sembiring \& Ompusunggu, 2016).

Penyajian materi pada multimedia interaktif menggunakan model tutorial. Model ini mengandung unsur panduan pembelajaran yang dilengkapi dengan tutor dan alat pengontrol oleh siswa, kemudian sistem dapat menampilkan informasi yang sesuai dengan pengoperasian yang dilakukan oleh pengguna (Diansyah, 2015. Model ini tidak jauh berbeda dengan metode pembelajaran tradisional yaitu guru menyampaikan pelajaran dan siswa menerimanya. Namun, menggunakan media yang memanfaatkan teknologi, tentu dapat ditambahkan ilustrasi menarik sehingga siswa menjadi lebih termotivasi untuk mempelajarinya seperti yang dijelaskan dalam (Nandi, 2016) bahwa media interaktif ini sebagai pengganti manusia yang bertindak sebagai instruktur. Selain itu, model tutorial merupakan metode alternatif yaitu bacaan, demonstrasi, pengalaman yang membutuhkan respon serta ada ujian (Prayoga, Sudarma, \& Tegeh, 2016).

Informasi yang disajikan pada multimedia interaktif ini berupa teks, gambar, animasi, dan suara. Media ini dirancang sesuai kebutuhan siswa sehingga dapat menambah motivasi siswa dalam belajar disertai dengan peningkatan pengetahuan dan pengayaan terhadap materi tentang hewan dan tumbuhan langka. Oleh sebab itu, kegiatan penelitian ini adalah (1)pembuatan sebuah media interaktif untuk pembelajaran tentang hewan dan tumbuhan langka bagi siswa sekolah dasar; (2)kemudian menganalisis media ini berdasarkan unsur interaktifitasnya sebagai media pembelajaran; (3)serta menganalisis keefektifan media pembelajaran berdasarkan nilai yang diperoleh siswa melalui pengujian dalam bentuk menjawab soal-soal dalam 2 tahap yaitu sebelum menggunakan media dan sesudah menggunakan media interkatif yang dihasilkan. Oleh sebab itu, metode pembuatan media menggunakan metode Luther-Sutopo yang dipandang mudah digunakan karena tahapannya sistematis dan disusun secara terprogram (Binanto, 2010) serta model ini dikenal sebagai model produk pembelajaran berbantuan komputer (Handikha, 2013).

Kontribusi dari penelitian diharapkan dapat dimanfaatkan oleh siswa karena dapat memberikan pengalaman belajar yang baru dengan pemanfaatan teknologi, sebagai media bantu pembelajaran bagi siswa Sekolah Dasar (SD) khususnya kelas III untuk lebih memahami materi hewan dan tumbuhan langka serta lebih peduli untuk menjaga kelestariannya agar tidak terancam punah. Berdasarkan hal tersebut diharapkan dapat meningkatkan efektifitas belajar siswa dalam memahami materi yang diberikan di sekolah.

104 | Evaliata Br Sembiring et al.: Multimedia Interkatif Pengenalan Hewan dan Tumbuhan Langka... 


\section{METODE}

Metode penelitian yang digunakan dalam pembuatan multimedia interaktif adalah Luther Sutopo yang terdiri dari concept, design, material collecting, assembly, testing dan distribution selanjutnya hasil pengujian kemudian dianalisis tentang interaktifitas dan kefektifan media pembelajaran seperti diilustrasikan pada Gambar 1.

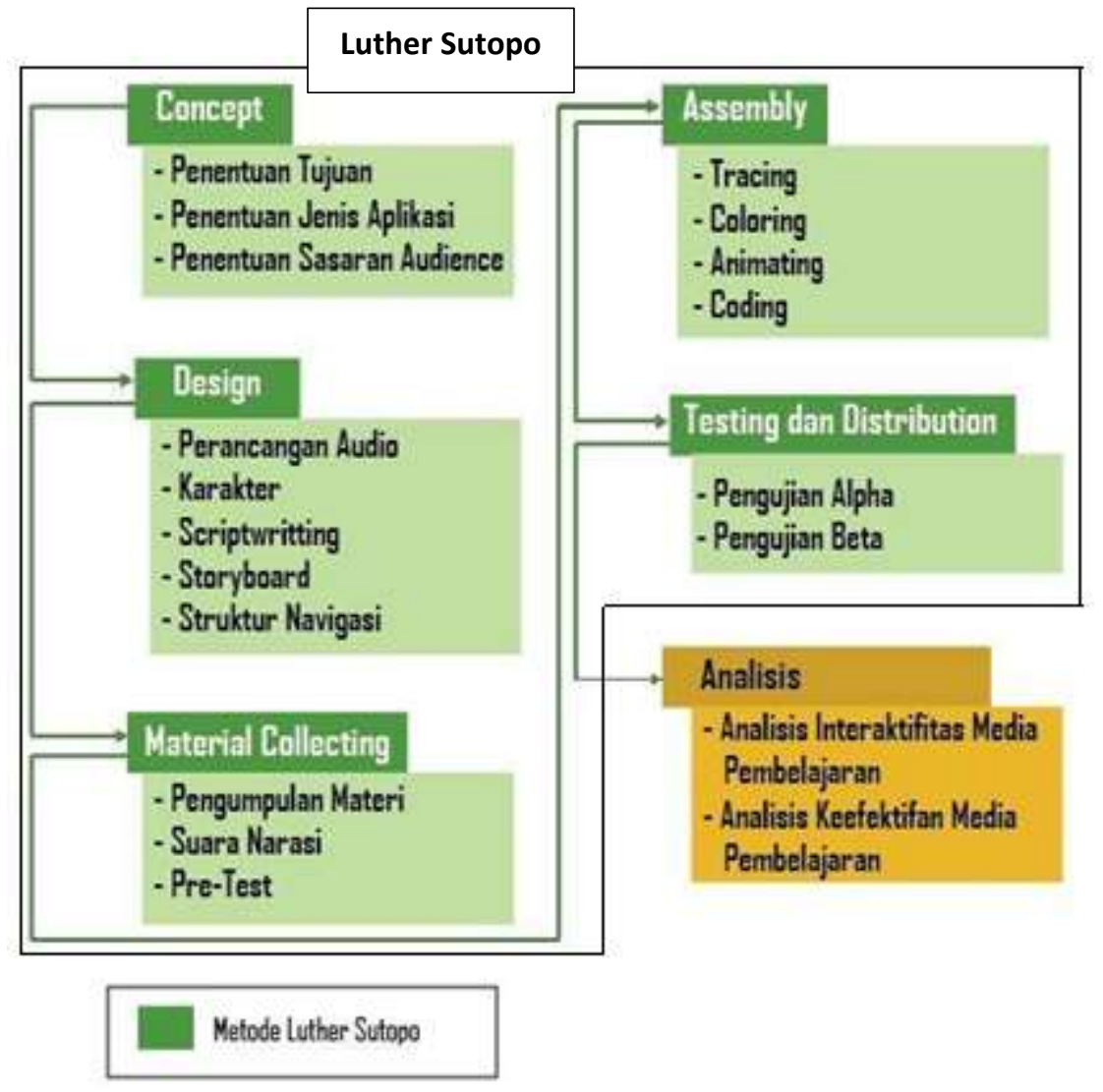

\section{Gambar 1 Tahapan Pembuatan Multimedia Interaktif dan Analisis}

\section{Konsep (Concept)}

Konsep produk sebagai media pembelajaran interaktif yang dibuat terdiri dari tujuan, sasaran pengguna dan jenis aplikasi yang dibuat antara lain:

a. Tujuan pembuatan multimedia interaktif sebagai media pembelajaran untuk membantu siswa memahami materi tentang hewan dan tumbuhan langka.

b. Sasaran pengguna (audience) yang ditargetkan adalah siswa kelas III Sekolah Dasar (SD).

c. Jenis aplikasi yang dihasilkan adalah produk dalam bentuk multimedia interaktif.

Pemilihan konsep multimedia interaktif untuk pengenalan hewan dan tumbuhan langka sebagai media pembelajaran ini juga berdasarkan beberapa aspek seperti pemilihan materi yang dijelaskan, karakter yang tepat dengan sasaran audience, audio yang cocok untuk target pengguna, dan gerakan animasi yang tepat sehingga materi dapat tersampaikan kepada sasaran (audience). 


\section{Perancangan (Design)}

Perancangan yang dilakukan meliputi perancangan audio, pembuatan struktur navigasi, perancangan karakter dan objek lain yang digunakan dalam produk, scriptwriting, dan storyboard.

a. Audio yang digunakan pada produk disesuaikan dengan materi pembelajaran yang disampaikan yaitu berfokus pada suara narasi. Konten ini diperoleh melalui proses perekaman suara dan menggunakan format (wav) karena mendukung tool yang digunakan dalam pembuatan media interaktif ini.

b. Struktur Navigasi yang digunakan dalam media interaktif ini seperti ditunjukkan pada Gambar 2. Struktur navigasi yang digunakan adalah model hirarki agar pengguna dapat menulusuri konten atau materi dari titik cabang atau titik awal dan menemukan halaman dengan mudah.

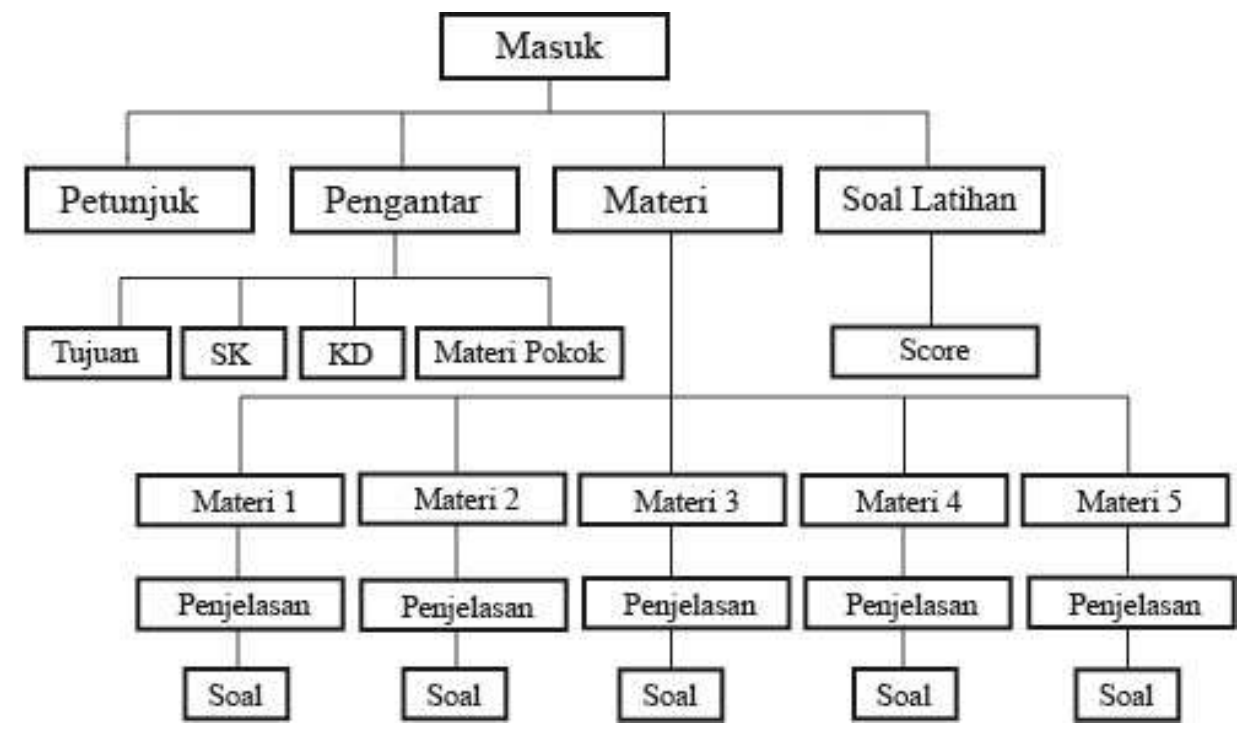

Gambar 2 Struktur Navigasi Multimedia Interaktif Pengenalan Hewan dan Tumbuhan Langka

c. Desain Karakter dan Objek terdiri dari karakter anak yang akan berperan menjadi tutor dan jenis-jenis hewan dan tumbuhan langka yang akan dipelajari oleh pengguna. Karakter dan Objek lainnya ini merupakan asset atau material yang akan menjadi konten dalam produk multimedia interaktif. Beberapa hasil rancangan karakter dan objek ditunjukkan pada Tabel 1.

Tabel 1 Desain Karakter dan Objek

\begin{tabular}{|l|l|l|}
\hline & $\begin{array}{l}\text { Karakter ini bernama } \\
\text { Miranti yang berumur } \\
9 \text { tahun dengan tinggi } \\
110 \mathrm{~cm} \text {. Pemilihannya } \\
\text { agar disesuaikan } \\
\text { dengan target } \\
\text { pengguna. }\end{array}$ \\
\end{tabular}

106 | Evaliata Br Sembiring et al.: Multimedia Interkatif Pengenalan Hewan dan Tumbuhan Langka... 


\begin{tabular}{|lll|}
\hline $\begin{array}{l}\text { Salah satu desain } \\
\text { tumbuhan langka } \\
\text { yaitu bunga Bangka. } \\
\text { Desain objek lainnya } \\
\text { lebih jelas di bagian } \\
\text { storyboard. }\end{array}$ & $\begin{array}{l}\text { Salah satu objek } \\
\text { yang digunakan } \\
\text { sebagai untuk set } \\
\text { lingkungan adalah } \\
\text { pohon tumbang. } \\
\text { Objek lainnya yang } \\
\text { termasuk kategori } \\
\text { ini adalah tombol } \\
\text { menu penggunaan } \\
\end{array}$ \\
& produk dan lainnya. \\
\hline
\end{tabular}

d. Scriptwriting yang dirancang terdiri dari 25 scene. Bentuk scriptwriting yang dirancang menggunakan bentuk narasi. Salah satu bentuk script yang dirancang seperti Scene 6.

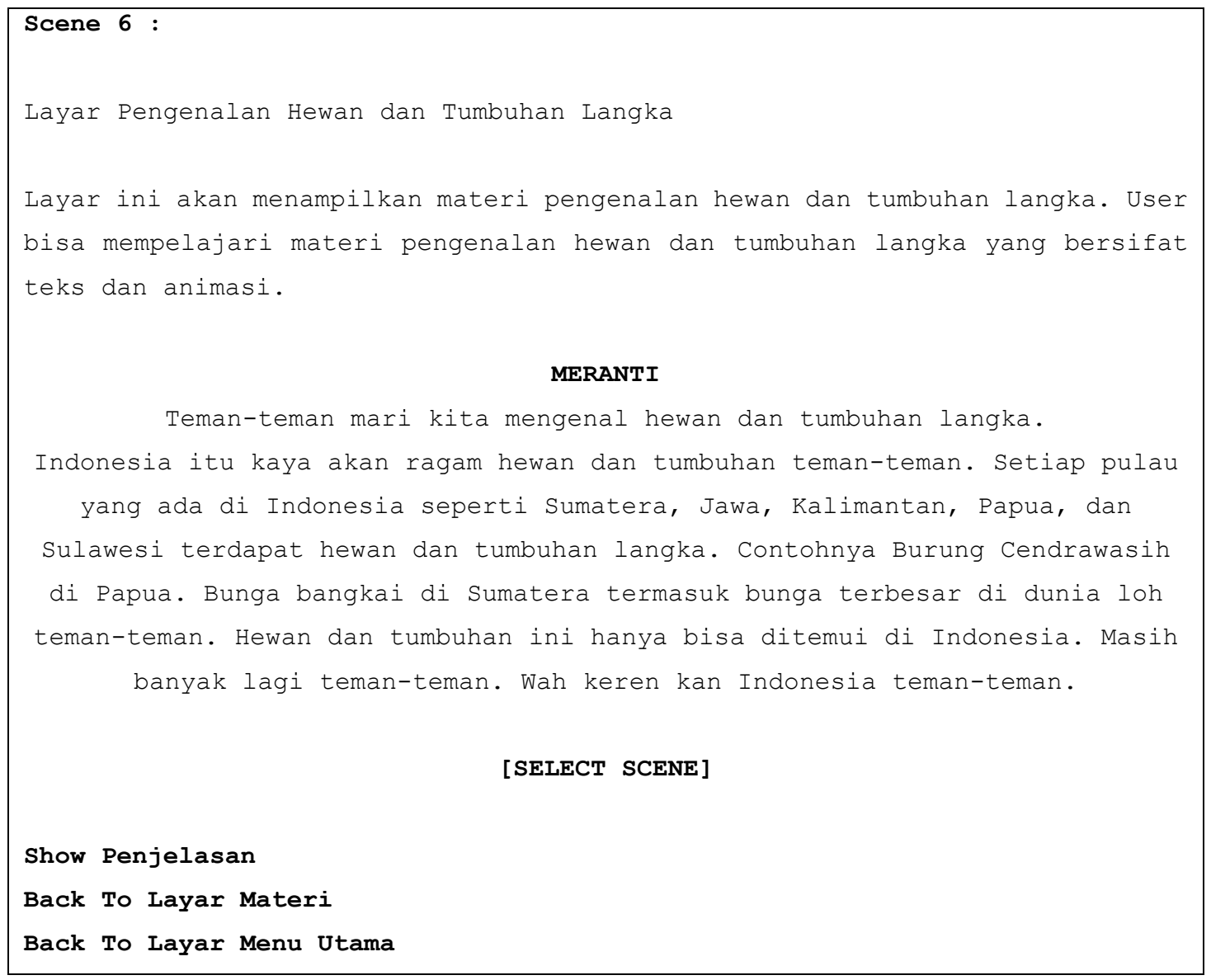

e. Storyboard yang dirancang mengandung informasi tentang scene, sketsa gambar, informasi audio, ukuran frame, informasi tombol (button), dan deskripsi layout. Salah satu storyboard yang dirancang seperti storyboard pada scene 6 . 


\begin{tabular}{l}
$\begin{array}{l}\text { Scene Name : } \\
\text { Layar Pengenalan Hewan dan Tumbuhan Langka }\end{array}$ \\
\hline \\
Audio : \\
Materi1.wav
\end{tabular}

\section{Pengumpulan Materi (Material Collecting)}

Materi-materi yang dibutuhkan dalam multimedia interaktif ini adalah audio, materi pengetahuan tentang hewan dan tumbuhan langka, soal-soal yang digunakan beserta kunci jawaban, serta objek pendukung lainnya.

a. Audio adalah hasil rekaman yang digunakan dalam format (wav)

b. Materi dan soal adalah berdasarkan buku Tematik Terpadu Perkembangbiakan Hewan dan Tumbuhan

Tema 1 Kelas III SD/MI Kurikulum 2013, dari Kemendikbud yang terdiri dari 5 sub materi yaitu :

$\checkmark$ Pengenalan Hewan dan Tumbuhan Langka

$\checkmark$ Hewan Langka di Indonesia diantaranya yaitu komodo, gajah, burung cendrawasih, harimau, anoa.

$\checkmark$ Tumbuhan Langka di Indonesia diantaranya yaitu bunga rafflesia, bunga bangkai, gaharu, dan pohon cendana.

$\checkmark$ Penyebab berkurangnya hewan dan tumbuhan langka di Indonesia di antaranya yaitu aktivitas manusia dan bencana alam.

$\checkmark$ Pelestarian hewan dan tumbuhan langka di Indonesia diantaranya yaitu suaka margasatwa, cagar alam, perlindungan hutan, taman nasional, taman laut, dan kebun binatang.

\section{Pembuatan Multimedia Interaktif (Assembly)}

Proses pembuatan produk atau media ini diawali dengan persiapan asset yaitu pembuatan karakter dan objek pendukung melalui tracing, coloring, animating, dan coding. Bersamaan dengan itu juga melakukan pembuatan template multimedia interaktif, dan pembuatan komponen pendukung multimedia interaktif lainnya menggunakan Adobe Flash Profesional CS6 dengan memanfaatkan Action Script 3.0 untuk mengatur menu pilihan sebagai fitur interaktifitas dengan pengguna. Salah satu pembuatan ini seperti pembuatan karakter yang diilustrasikan pada

108 | Evaliata Br Sembiring et al.: Multimedia Interkatif Pengenalan Hewan dan Tumbuhan Langka... 
gambar 3. Objek-objek pendukung lainnya serta pembuatan konten dan layout menggunakan langkah-langkah yang sama.

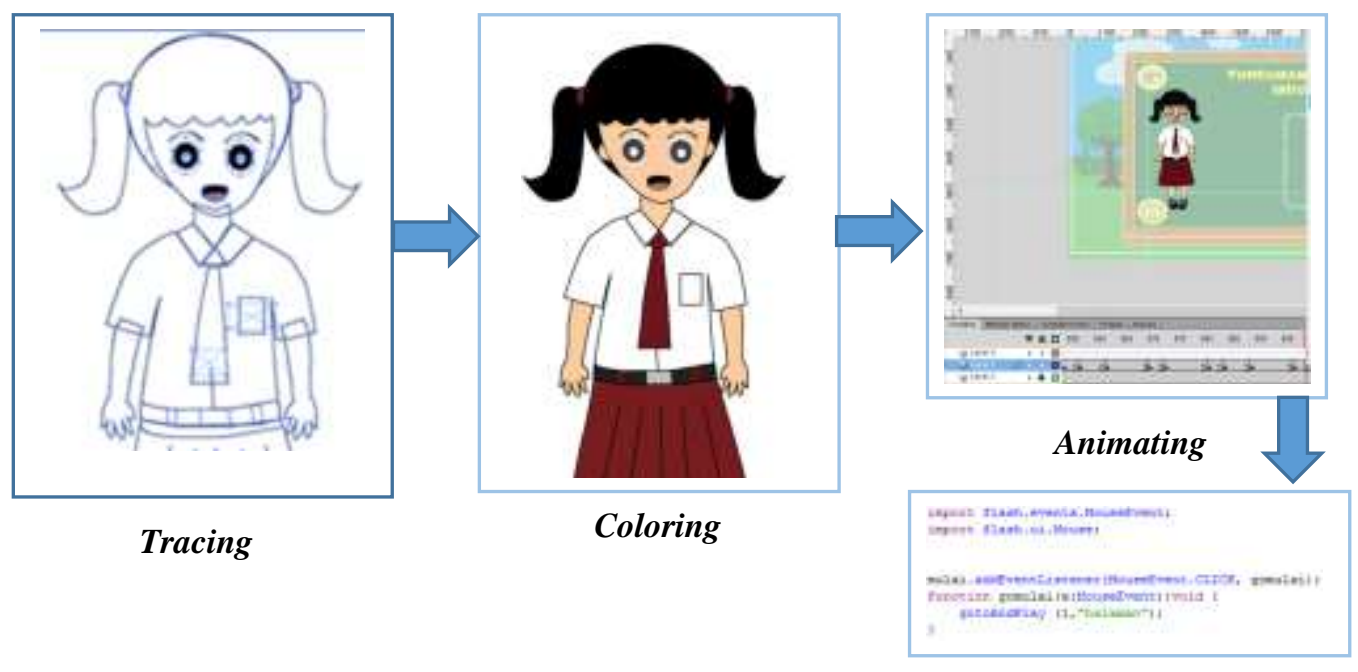

Gambar 3 Proses Pembuatan Karakter dan Objek

\section{Coding}

\section{Pengujian dan Distribusi Multimedia Interaktif (Testing \& Distribution)}

Pengujian dilakukan melalui 2 tahap yaitu pengujian alpa dan pengujian beta. Pengujian alpha dilakukan untuk mengetahui kesesuaian multimedia interaktif dengan hasil rancangan dan fungsionalitas serta fitur sudah berjalan dengan benar. Terdapat dua kali revisi dengan penambahan beberapa objek dan pengaturan volume suara untuk menyempurnakan hasil ynag maksimal. Setelah melakukan pengujian alpha selanjutnya melakukan pengujian beta yaitu menguji produk kepada target pengguna yaitu siswa kelas 3 SD Negeri 010 Nongsa Batam dengan 30 responden. Bentuk pengujian yang dilakukan dengan mencoba produk oleh siswa kemudian dilakukan pengisian kuisioner yang dibantu oleh pengajar dan tim. Ketika pengujian Alpha sudah selesai dilakukan, maka proses distribusi sudah dapat dilakukan dengan mengemas produk dalam format (.exe) sehingga dapat dipublikasikan kepada khalayak ramai. Dalam hal ini, dicoba kepada target pengguna untuk dianalisis interaktifitas dan keefektifannya sebagai media pembelajaran.

\section{HASIL DAN PEMBAHASAN}

Hasil pengujian alpha adalah konsep dan rancangan melalui storyboard dan scriptwriting berhasil diimplementasikan kedalam bentuk visual dan interaktif. Beberapa tambahan objek dilakukan untuk menyempurnakan hasil agar lebih maksimal. Objek yang ditambahkan seperti background pada scene 1 dan scene 2. Perubahan ini dipengaruhi oleh penggunaan bentuk storyboard yang sederhana tanpa dilengkapi dengan narasi, time, audio, set lingkungan secara detail. Namun secara keseluruhan, implementasi dapat dikatakan sesuai dengan rancangan berdasarkan beberapa kesesuaian yang dapat dilihat berdasarkan objek yang digunakan serta narasi yang ditentukan pada setiap scene. Objek yang digunakan pada setiap scene sesuai dengan hasil rancangan. Narasi yang berisi materi pengenalan hewan dan tumbuhan langka sudah sesuai dengan scriptwriting. Hasil akhir yang diperoleh adalah materi disajikan dalam bentuk tutorial dengan tutor diperankan oleh karakter utama yang dilengkapi dengan audio dan animasi $2 \mathrm{D}$ yang cocok untuk anak-anak, sedangkan latihan disajikan secara random 
sehingga dalam media ini dilengkapi dengan bank soal yang terdiri dari 50 soal. Berdasarkan hasil pengujian ini kemudian dilakukan analisis interaktifitas dan keefektifitas produk sebagai media pembelajaran.

\section{Analisis Interaktifitas Sebagai Media Pembelajaran}

Pengujian multimedia interaktif ini dilakukan berdasarkan aspek interaktif menggunakan parameter Thorn (2006) yang terdiri dari kemudahan navigasi, kandungan kognisi, presentasi informasi, integrasi media, artistik dan estetika, serta fungsi keseluruhan. Hasil yang diperoleh ditunjukkan melalui grafik persentase masing-masing parameter seperti ditunjukkan pada Grafik 1.

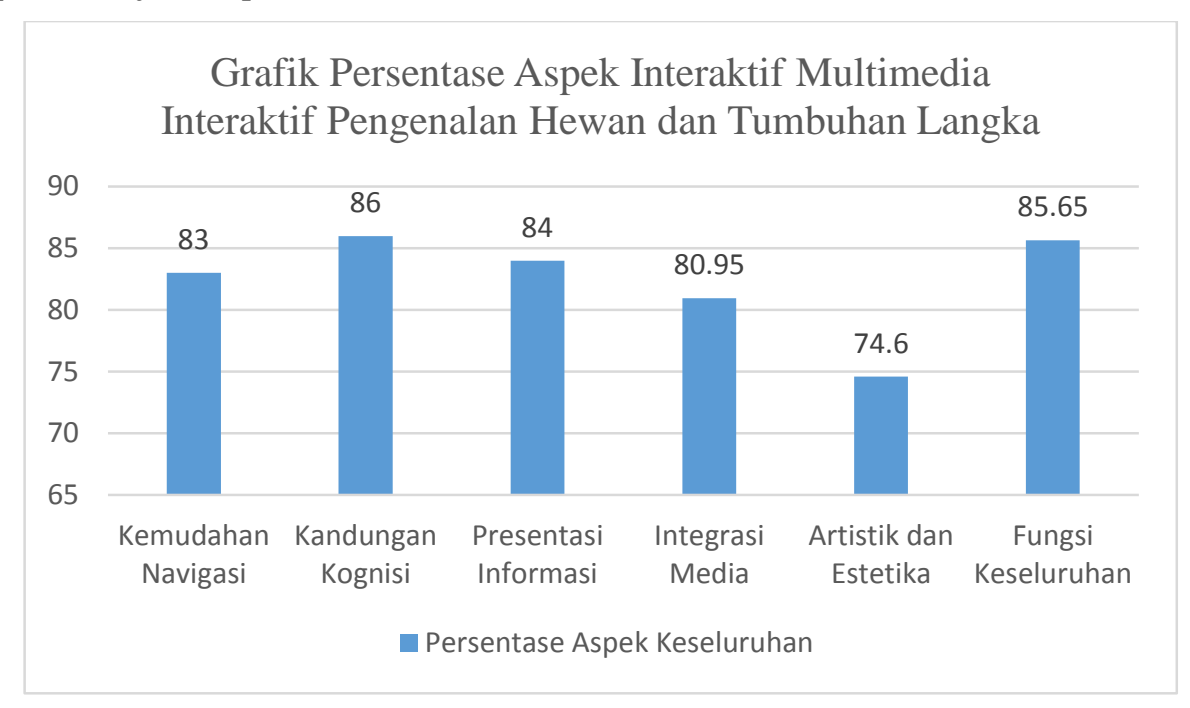

\section{Grafik 1 Grafik Persentase Aspek Interaktif Produk yang dihasilkan}

Secara keseluruhan, media yang dihasilkan sudah memiliki fitur interaktifitas yang baik yaitu melalui menu pilihan dalam bentuk tombol yang mudah digunakan dan berfungsi dengan baik. Hasil respon dari pengguna mencapai rata-rata persentase sebanyak $82,4 \%$ menyatakan sangat setuju media ini cukup interaktif sebagai media pembelajaran. Persentase tertinggi dari 6 parameter yang diuji adalah aspek kandungan kognisi yang mencapai $86 \%$ yang berarti materi yang disajikan dapat disampaikan dengan baik dan jelas serta dilengkapi dengan petunjuk penggunaan yang mudah digunakan oleh anak-anak. Aspek terendah adalah artistik dan estetika yang mencapai $74,6 \%$. Oleh karena itu, pengembangan produk multimedia interaktif perlu memperhatikan aspek artistik dan estetika khususnya untuk responden dalam usia anak-anak. Hal ini karena anak-anak lebih suka gambar yang menarik dan kreatif, serta tulisan yang jelas dibaca.

\section{Analisis Efektifitas Sebagai Media Pembelajaran}

Keefektifan multimedia interaktif pengenalan hewan dan tumbuhan langka sebagai media pembelajaran di sekolah dapat dianalisis berdasarkan hasil pengujian pre-test dan post-test terhadap responden yang sama. Pre-test dilaksanakan secara manual yaitu responden mendengar penyampaian dari pengajar kemudian melakukan latihan menggunakan kertas. Setelah produk berhasil dibuat dan sudah melalui pengujian alpha selanjutnya dilakukan pengujian beta yang disebut dengan post-test. Hasil dari kedua pengujian ini, diperoleh bahwa terjadi peningkatan pemahaman responden tentang hewan dan tumbuhan langka. Tingkat kenaikan setiap responden beraneka ragam seperti digambarkan pada Grafik 2 berikut ini.

110 | Evaliata Br Sembiring et al.: Multimedia Interkatif Pengenalan Hewan dan Tumbuhan Langka... 


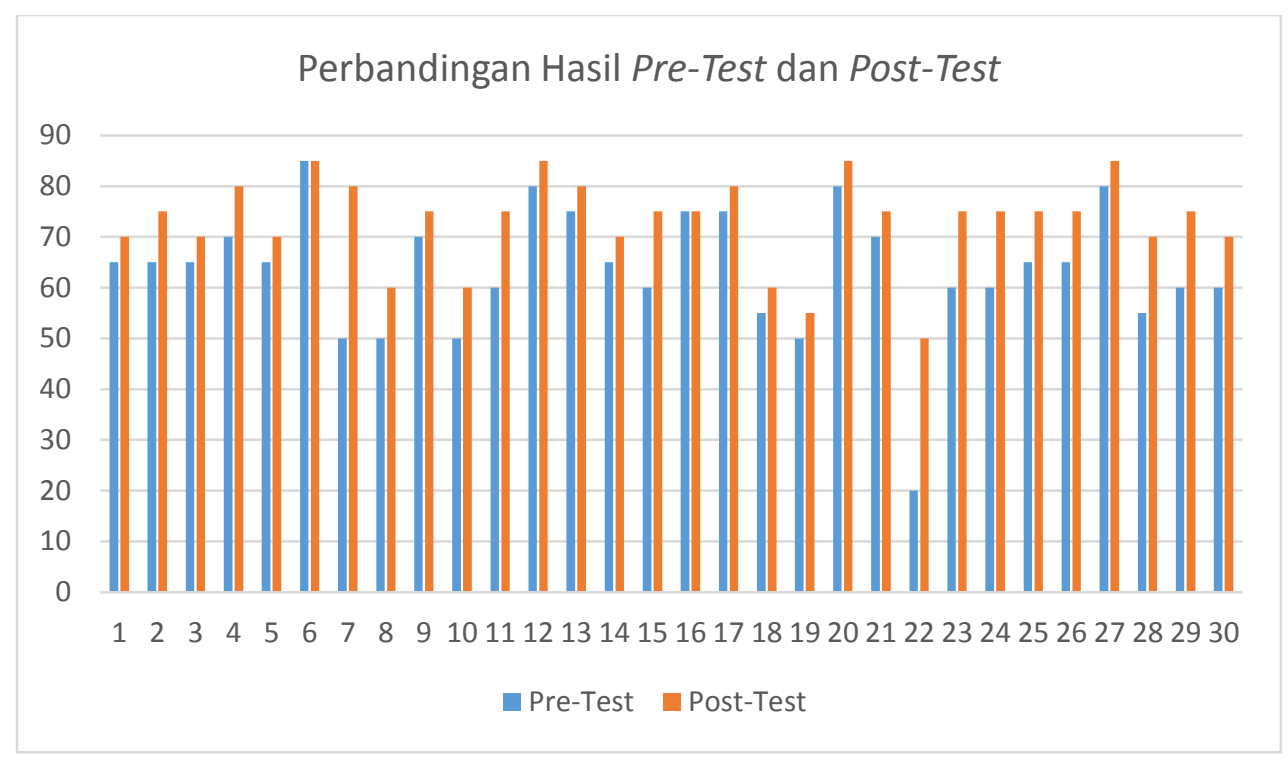

Grafik 2 Persentase Nilai Mengerjakan Soal pada Pre-Test dan Post-Test

Berdasarkan KKM yang diterapkan pada SDN 010 Nongsa sebagai target penelitian, bahwa seorang siswa dinyatakan tuntas minimal memiliki nilai 66,7 untuk pelajaran IPA. Dari hasil grafik perbandingan nilai pre-test dan post-test menunjukkan bahwa hasil tuntas siswa pada saat melakukan post-test mengalami peningkatan sebesar 50\% yang awalnya dengan nilai persentase pre-test sebesar 33,3\% dan meningkat menjadi 83,3\%. Hasil yang diperoleh responden dikategorikan menjadi nilai Tuntas dan Tidak Tuntas seperti ditunjukkan pada Grafik 3.

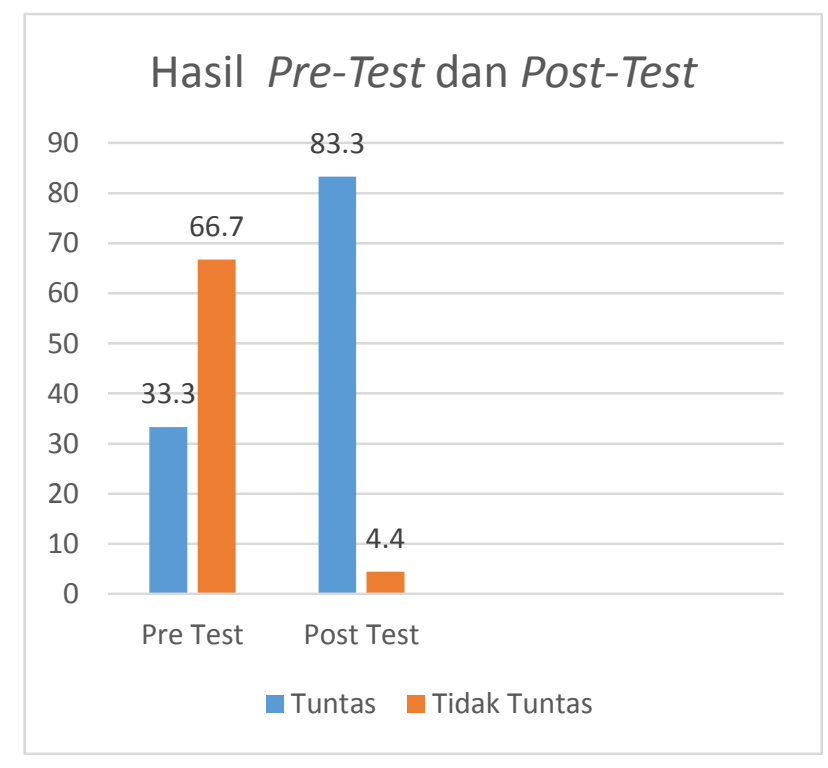

Grafik 3 Persentase Hasil Pembelajaran melalui Pre-Test dan Post-Test

\section{KESIMPULAN}

Beberapa kesimpulan yang diperoleh adalah sebagai berikut:

1. Multimedia interaktif Pengenalan Hewan dan Tumbuhan Langka berhasil dibuat sesuai dengan hasil rancangan dengan menerapkan model Tutorial. 
a. Produk yang dihasilkan dalam bentuk .exe sehingga dijalankan pada perangkat laptop dan komputer tanpa bergantung pada software tertentu. Penyajian materi menerapkan model tutorial dan evaluasi melalui latihan soal yang disajikan secara acak untuk setiap pengguna.

b. Multimedia interaktif pengenalan hewan dan tumbuhan langka layak digunakan sebagai media pembelajaran berdasarkan aspek interaktif dengan pencapaian sebesar $82,4 \%$. Namun dari enam unsur aspek interaktif ini ada satu aspek yang hanya mencapai 74,6\% yaitu aspek artistik dan estetika. Oleh karena itu sangat penting memperhatikan karakteristik target pengguna dalam membangun produk multimedia khusus media pembelajaran.

2. Multimedia interaktif pengenalan hewan dan tumbuhan langka sudah efektif digunakan sebagai media pembelajaran untuk siswa kelas III Sekolah Dasar berdasarkan perbandingan hasil pre-test dan post-test yang menunjukkan bahwa hasil tuntas siswa pada saat melakukan post-test mengalami peningkatan sebesar 50\% yang awalnya dengan nilai persentase pre-test sebesar 33,3\% dan meningkat menjadi $83,3 \%$.

\section{DAFTAR PUSTAKA}

Abidin, M. M., Purnama, B. E., dan Nugroho, G. K. (2013). Pembangunan Media Pembelajaran Teknik Komputer Jaringan Kelas X Semester Ganjil Pada Sekolah Menengah Kejuruan Taruna Bangsa Pati Berbasis Multimedia Interaktif. IJNS-Indonesian Journal on Networking and Security, 4(3).

Binanto, Iwan. 2010. Multimedia Digital Dasar Teori dan Pengembangannya. Penerbit C.V ANDI OFFSET

Diansyah, A. N. (2015). Penerapan Multimedia Interaktif Model Tutorial Terhadap Peningkatan Pemahaman Konsep Siswa Pada Mata Pelajaran Teknologi Informasi dan Komunikasi. Jurnal PETIK, 1(1), 11-18

Handikha, I. M. D., Agung, A. A. G., dan Sudatha, I. G. W. (2013). Pengembangan Multimedia Pembelajaran Interaktif Model Luther Pada Mata Pelajaran Ipa Kelas Viii Semester Ganjil Tahun Pelajaran 2012/2013 Di Smp Negeri 1 Marga Kabupaten Tabanan. Jurnal Edutech, 1(2).

Nandi, N. (2016). Penggunaan Multimedia Interaktif dalam Pembelajaran Geografi di Persekolahan. Jurnal Geografi Gea, 6(2).

Permana, M. S., dan Damiri, D. J. (2014). Pengembangan Media Pembelajaran Interaktif Ilmu Pengetahuan Alam (IPA) Berbasis Multimedia. Jurnal Algoritma, 11.

Prayoga, G. S., Sudarma, I. K., \& Tegeh, I. M. (2016). Pengembangan Multimedia Interaktif Model Tutorial Pada Mata Pelajaran PKN Kelas VIII Semester Genap Di SMP Negeri 6 SingaRaja Tahun Pelajaran 2015/2016. Jurnal Teknologi Pendidikan Universitas Pendidikan Ganesha, 5(2).

Rosyida, S. (2017, Februari). Multimedia Interaktif sebagai Media Pembelajaran tentang Pengenalan Vitamin yang Terkandung di Dalam Buah. Jurnal Teknik Informatika STMIK Antar Bangsa, 3, 17-23.

Sembiring, E. B., \& Ompusunggu, J. (2016). Rancang Bangun Multimedia Interaktif Pembelajaran Alat Musik Tradisional Melayu menggunakan Metode Godfrey. Applied Business And Engineering Conference (pp. 274-281). Pekan Baru: Politeknik Caltex Riau.

Thorn, W. J. (1995, April). Points to Consider when Evaluating Interactive Multimedia. Retrieved July 10, 2013, from The Internet TESL Journal: http://iteslj.org/Articles/Thorn-EvalueConsider.html

112 | Evaliata Br Sembiring et al.: Multimedia Interkatif Pengenalan Hewan dan Tumbuhan Langka... 